\title{
Kumlu tın ve killi tın toprakta kokopit uygulamasının tarla kapasitesi ve devamlı solma noktası üzerine etkisi
}

\section{Effect of cocopeat application on field capacity and permanent wilting point in sandy loam and clay loam soil}

\author{
Pelin ALABOZ ${ }^{1}$ (D), Talip ÇAKMAKCI ${ }^{2}$ (i) \\ ${ }^{1}$ Isparta Uygulamalı Bilimler Üniversitesi, Ziraat Fakültesi, Toprak Bilimi ve Bitki Besleme Bölümü, 32100, Isparta \\ ${ }^{2}$ Van Yüzüncü Yıl Üniversitesi, Ziraat Fakültesi, Biyosistem Mühendisliği Bölümü, 65080, Van \\ Sorumlu yazar (Corresponding author): T. Çakmakc1, e-posta (e-mail): talipcakmakci@yyu.edu.tr \\ Yazar(lar) e-posta (Authore-mail): pelinalaboz@isparta.edu.tr
}

\section{MAKALE BİLGİSI}

Alınış tarihi 16 Aralık 2019

Düzeltilme tarihi 01 Nisan 2020

Kabul tarihi 07 Nisan 2020

\section{Anahtar Kelimeler:}

Kokopit

Tarla kapasitesi

Toprak düzenleyicileri

Toprak suyu içeriği

Devamlı solma noktası

\begin{abstract}
ÖZ
Toprak nem sabiteleri, sulama suyu miktarlarının belirlenmesinde kullanılan önemli parametrelerin başında gelmektedir. Bu çalışmada; kokopit uygulamalarının, farklı tekstürlere sahip topraklarda suyun tutulması üzerine etkisi araştırılmıştır. Bu amaçla, kumlu tın ve killi tın tekstürlü topraklara 4 farklı dozda $(\% 0,1,2,3)$ kokopit uygulanarak, 3 farklı süreyle inkübasyona [1 ay (T1), 2 ay (T2), 3 ay (T3)] bırakılmış ve toprakların tarla kapasitesi ile devamlı solma noktası belirlenmiştir. İncelenen özelliklerde inkübasyon süresine bağlı olarak belirgin bir artış gözlenmemiş ve istatistiksel olarak önemli bulunmamıştır. Her iki tekstür grubu için toprakların tarla kapasitesinde en yüksek artış (yaklaşık \%8 oranında) \%3 kokopit uygulamasıyla T3 inkübasyon süresiyle sağlanmıștır. Toprakların devamlı solma noktasında en belirgin artış kumlu tın tekstür grubunda \%3 uygulamasının T3 inkübasyon süresinde (\%3.81) bulunmuştur. Ayrıca, her iki tekstür grubu için materyalin ekonomik olarak uygulanabilirliği göz önüne alındığında devamlı solma noktasında optimum artış \%2 kokopit uygulamasıyla elde edilmiştir.
\end{abstract}

\section{ARTICLE INFO}

Received 16 December 2019

Received in revised form 01 April 2020

Accepted 07 April 2020

\section{Keywords:}

Cocopeat

Field capacity

Soil regulators

Soil water content

Permanent wilting point

\begin{abstract}
Soil moisture constants are the main parameters used to determine the amount of irrigation water. In this study, the effect of cocopeat application on the retention of water in soils with different textures was investigated. For this purpose, four different doses $(0,1,2,3 \%)$ of cocopeat were applied to sandy loam and clay loam textured soils for three different incubations [1 month (T1), 2 months (T2), 3 months (T3)] and soil field capacity and moisture content at permanent wilting point were determined. At the end of the study, it was observed that there weren't significant increases in the investigated properties depending on the incubation time and these were not statistically significant. The highest increase in field capacity (approximately 8\%) of soils for both texture groups were obtained from $3 \%$ cocopeat application with the T3 incubation period. The most significant increase in the permanent wilting point was found in sandy loam texture for 3\% application and T3 incubation time $(3.81 \%)$. Moreover, considering its economic applicability, it had been determined that optimum increase in permanent wilting point was achieved by $2 \%$ cocopeat application for both texture groups.
\end{abstract}

\section{Giriş}

Kurak ve yarı kurak bölgelerde, düşük kil ve organik madde içeriğine sahip topraklarda su tutma kapasitesi (Abdelfattah 2013) ve verimlilik düşüktür (Xu ve ark. 2015). Kuraklık sorununun gün geçtikçe arttı̆g 1 ülkemizde, toprakların su tutma kapasitelerinin arttırılması, bitkilerin toprak suyundan etkin bir şekilde yararlanması için önemlidir. Toprakta farklı uygulamalara yer verilmesi tarımın sürdürülebilirliği açısından önemli bir seçenek haline gelmiştir (Bhardwaj ve ark. 2007). Bu sebeple toprakların fiziksel, kimyasal ve biyolojik özelliklerini iyileştirmek için farklı toprak düzenleyicileri kullanılmaktadır (Thombare ve ark. 2018). Zeolit (Ippolito ve ark. 2011), kireç, polyacrylamide (PAM), biyokatı (Özdemir ve ark. 2014), balmumu (Bhosale ve ark. 2012), pomza (Korkanç ve ark. 2017), saman malçları, kağıt pelet (Meral ve ark. 2015) gibi 
bazı düzenleyicilerin toprak koşullarını iyileştirdiği araştırmacılar tarafindan rapor edilmiştir. Yine, hem doğal hem de sentetik toprak düzenleyicileri; bitki kök bölgesinde gerekli olan suyun bulunmasına önemli ölçüde katkı sağlamaktadır (Vijayalakshmi ve ark. 2012).

Hindistan cevizinin kabuğu (kokopit), bitki yetiştirme ortamlarında kullanılan oldukça lifli yapıya sahip, su tutma kapasitesi yüksek bir materyaldir (Abad ve ark. 2002). Kokopit' in yetiştirme ortamı olarak kullanılabilmesini araştıran Evans ve ark. (1996) ile Ilahi ve Ahmad (2017), kokopit'in kuru ağırlığının \%750-1100'ü kadar su tutma özelliğine sahip olduğunu belirtmişlerdir. Bu özelliğinden dolayı, kokopit su ve besin elementi tutulumunun düşük olduğu topraklarda düzenleyici olarak kullanılabilmektedir Arachchi ve Somasiri (1997).

$\mathrm{Bu}$ çalışmanın amacı; farklı tekstürlere (kumlu tın ve killi tın) sahip topraklara kokopit uygulamalarının $(\% 0,1,2,3)$, inkübasyon süresindeki değişime bağlı olarak bazı nem sabiteleri üzerindeki (tarla kapasitesi ve devamlı solma noktası) etkisini belirlemektir.

\section{Materyal ve Metot}

Bu çalışma, Isparta Uygulamalı Bilimler Üniversitesi Ziraat Fakültesi, Toprak Bilimi ve Bitki Besleme Bölümü Laboratuvarında yürütülmüştür. Arazi koşullarını yansıtması ve üreticiye uygulama kolaylığı olması adına hem toprak hem de kokopit 4 mm'lik elekten geçirilerek denemede kullanılmıştır. Toprak ve kokopit'in bazı özellikleri Çizelge 1'de belirtilmiştir. Killi tın toprak, üniversitenin çiftlik arazisinden kumlu tın bünyeli topraklar ise bölgede yetiştiriciliği yapılan bağ'lık alanlardan temin edilmiştir. Kokopit bölgede bulunan bir tarım firmasından alınmıştır. Su tutma potansiyeli düşük olan kumlu topraklar bu çalışmada özellikle tercih edilmiş, killi bünye ise su tutma yönünden problemli olmasa da kumlu bünye ile karşılaştırma adına ve bölgede yaygın olan tekstür grubu olması ile tercih edilmiştir. Kumlu tın ve killi tın topraklar Ülgen ve Yurtsever (1988)'e göre ' düşük' organik madde içerikli, hafif alkalin reaksiyonlu (Jones 1984) ve "tuzsuz" (Dahnke ve Whitney 1988) olarak tanımlanmaktadır. Kokopit materyali ise asit (Jones 1984) karakterli, tuzsuz sınıfinda, su tutma kapasitesi ise kuru ağırlığının 8.37 katı olarak belirlenmiştir.
Denemede, 1'er kg'lık kumlu tın ve killi tın tekstürlü toprağa kuru ağırlık esasına göre $\% 0,1,2$ ve 3 (D0, D1, D2, D3) düzeylerinde elenmiş kokopit eklenerek homojen bir görünüme gelinceye kadar karıştırılmıştır. Kokopit-toprak karışımları plastik kapaklı kaplara konulmuş hava alması için üzerlerinden küçük delikler açılmıştır. Farklı inkübasyon sürelerine (1(T1), 2(T2), 3(T3) ay) tabi tutulan karışımlar oda sicaklığında $\left(25^{\circ} \mathrm{C} \pm 3^{\circ} \mathrm{C}\right)$ ve tarla kapasitesi'nin (TK) \%70'i seviyesine gelecek şekilde haftada bir sulanmıştır. Eksilen su miktarı ağırlık takibiyle kontrol edilmiş, TK'nın \%70'ine getirmek için gereken su miktarı hesaplanarak uygulanmıştır.

Deneme tesadüf parselleri deneme desenine göre 3 tekerrürlü olarak yürütülmüş, analizler üçer paralelli olarak yapılmıştır. Her inkübasyon süresi sonunda uygulama yapılan toprak-kokopit karışımından örneklemeler yapılarak tarla kapasitesi (TK) ve devamlı solma noktası (SN) belirlenmiştir.

Çalışmada kullanılan materyallerin $\mathrm{pH}$ ve EC değerleri Kacar (2009) ve US Salinity Laboratory Staff (1954)'a göre 1:1 toprak-su ve 1:10 kokopit-su süspansiyonları kullanılarak, organik madde içeriği değiştirilmiş Walkey-Black yöntemi, Eşdeğer \% $\mathrm{CaCO}_{3}$ ise Scheibler kalsimetresi ile belirlenmiştir (Kacar 2009). Mekanik analiz sonucu \% kum, silt ve kil dağılımlarında hidrometre yöntemi kullanılmıştır (Demiralay 1993). Toprakların tarla kapasitesi ve devaml solma noktas 1 belirlemelerinde 0.33 ve 15 bar basınçlarda tutulan nem miktarları basınç tencereleri yardımıyla (Demiralay 1993) gravimetrik olarak tespit edilmiştir. Çalışma sonunda elde edilen verilerin istatistiksel değerlendirilmesinde Minitab-19 paket programından yararlanılmıştır. Veriler varyans analizi ve Tukey çoklu karşılaştırma testi ile değerlendirilmiştir. (Minitap 2020).

\section{Bulgular ve Tartışma}

Farklı dozlarda kokopit uygulamalarının toprakların tarla kapasitesi ve devamlı solma noktası üzerine etkisini gösteren \%95 güven düzeyinde hipotez test sonucunun anlamlılığını veren $\mathrm{F}$ ve $\mathrm{P}$ değerleri (varyans analiz tablosu) Çizelge 2'de belirtilmiştir. Genel olarak doz uygulamalarının etkileri istatistiksel olarak \%1 ve daha düşük seviyelerde önemli bulunurken uygulamalar arasındaki interaksiyonlar istatistiksel olarak önemsiz $(\mathrm{P}<0.05)$ belirlenmiştir.

Çizelge 1. Toprağın ve kokopit'in bazı özellikleri.

Table 1. Some properties of soil and cocopeat.

\begin{tabular}{ccccccc}
\hline Materyal & $\begin{array}{c}\text { Kil } \\
(\%)\end{array}$ & $\begin{array}{c}\text { Silt } \\
(\%)\end{array}$ & $\begin{array}{c}\text { Kum } \\
(\%)\end{array}$ & $\begin{array}{c}\text { Organik madde } \\
(\%)\end{array}$ & $\begin{array}{c}\mathrm{CaCO}_{3} \\
(\%)\end{array}$ & $\begin{array}{c}\mathrm{EC} \\
\left(\mathrm{dS} \mathrm{m}^{-1}\right)\end{array}$ \\
\hline Kumlu tin & 18.05 & 20.90 & 61.05 & 1.25 & 12.1 & 7.84 \\
\hline Killi tın & 30.55 & 30.90 & 38.55 & 1.85 & 0.47 & 18.2 \\
\hline Kokopit & - & - & - & - & 0.58 & 6.01 \\
\hline
\end{tabular}

Çizelge 2. Varyans analiz sonuçları.

Table 2. Variance analysis results.

\begin{tabular}{|c|c|c|c|c|c|}
\hline \multirow{2}{*}{ Tekstür } & \multirow{2}{*}{ Uygulamalar } & \multicolumn{2}{|c|}{ Devamlı solma noktası \% } & \multicolumn{2}{|c|}{ Tarla kapasitesi \% } \\
\hline & & $\mathrm{F}$ & $\mathrm{P}$ & $\mathrm{F}$ & $\mathrm{P}$ \\
\hline \multirow{3}{*}{ Killi Tın } & Doz & 8.02 & 0.003 & 12.93 & 0.000 \\
\hline & İnkübasyon & 1.66 & 0.232 & 0.38 & 0.692 \\
\hline & Dozxİnkübasyon & 0.71 & 0.652 & 0.30 & 0.923 \\
\hline \multirow{3}{*}{ Kumlu Tin } & Doz & 5.37 & 0.014 & 29.87 & 0.000 \\
\hline & İnkübasyon & 1.46 & 0.272 & 0.05 & 0.955 \\
\hline & Dozxİnkübasyon & 0.62 & 0.711 & 0.80 & 0.585 \\
\hline
\end{tabular}


Killi topraklara kokopit uygulamalarının tarla kapasitesi (TK) üzerine etkisi Şekil 1'de belirtilmiştir. Uygulamaların ana etkilerinden doz uygulamaları istatistik olarak önemli seviyede değişim gösterirken $(\mathrm{P}<0.01)$ doz $\mathrm{x}$ inkübasyon etkileşimi önemli bulunmamıştır. İnkübasyon süresine bağlı olarak TK sirasıly $\% 26.55,26.47$ ve 27.37 olarak belirlenmiştir. T1 ve T2 inkübasyon süreleri sonucunda TK'daki nem seviyeleri birbirine oldukça benzerlik gösterirken, T3'de yaklaşık \%1'lik bir artış tespit edilmiştir (Şekil 1a). Artan doz uygulamalarına bağlı TK sirasiyla \%23.18, 25.65, 27.18 ve 31.17 olarak bulunmuştur. D0 dozu diğer uygulamalara göre istatistik olarak önemli farklılık göstermiştir. D1 ve D2 sonuçları birbirine benzer iken D3 uygulaması en yüksek tarla kapasitesi değeri ile diğer dozlardan istatistiksel olarak farklılık göstermiştir (Şekil 1a). Dozların inkübasyona bağlı değişimlerinde en düşük TK, T1'in D0'dozunda (\%23.18) en yüksek ise T3'ün D3 (\%31.89) dozunda belirlenmiştir (Şekil 1b). Kontrol uygulamasına kıyasla TK'da yaklaşık \%8'lik bir artış gözlenmiştir. Yine literatürdeki çalışmalarda, kokopit'in su tutma kapasitesi üzerinde pozitif etkiler gösterdiği bildirilmiştir (Kadıoğlu ve Canbolat 2019).

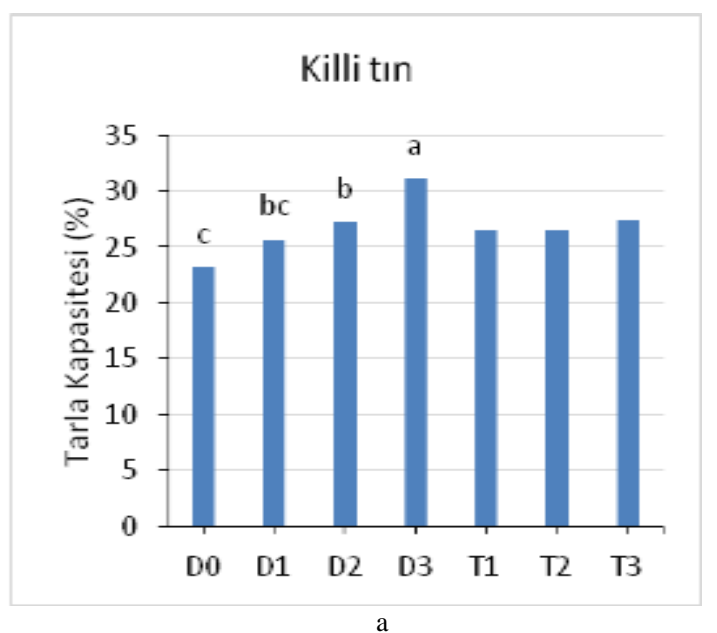

Kumlu topraklara uygulanan kokopit'in TK'üzerine etkileri Şekil 2'de belirtilmiştir. Kokopit uygulamalarında inkübasyon süreleri incelendiğinde sirasiyla elde edilen TK seviyeleri \%17.16, 17.04, 16.93'dür (Şekil 2a). İnkübasyon süresine göre TK'da bir değişimin olmaması parçalanma ayrışma olayının aktif olarak gerçekleşmeye başlamaması kaynaklı olabilmektedir. Organik materyaller farklı oranlarda $\mathrm{C} / \mathrm{N}$ oranlarına sahip olup bu oran parçalanma ayrışmayı etkilemekte, dolayısıyla zamana bağlı su tutma özelliklerinde farklılıklar görülmektedir (Yılmaz ve Alagöz 2008). Doz uygulamalarının etkisi incelendiğinde uygulamalara bağlı TK seviyelerindeki değişim istatistiksel olarak önemli bulunmuştur (P<0.01). D0 (\%13.98), D1 (\%16.44) ve D2 (\%16.11) dozlar1 istatistik olarak birbirine benzer iken D3 dozu (\%21.66) diğer dozlardan önemli seviyede farklılık göstermektedir (Şekil 2a). En düşük TK, T2'nin D0 dozunda (\%13.98) en yüksek ise T1'in D3 uygulamasında (\%22.98) belirlenmiştir. İnkübasyon süresinin farklı dozlardaki etkisi istatistiksel olarak önemli bulunmamıştır. D3 uygulaması kontrole göre kumlu tın toprağın TK'sında yaklaşık \%8'lik bir artış sağlamıştır (Şekil 2b).

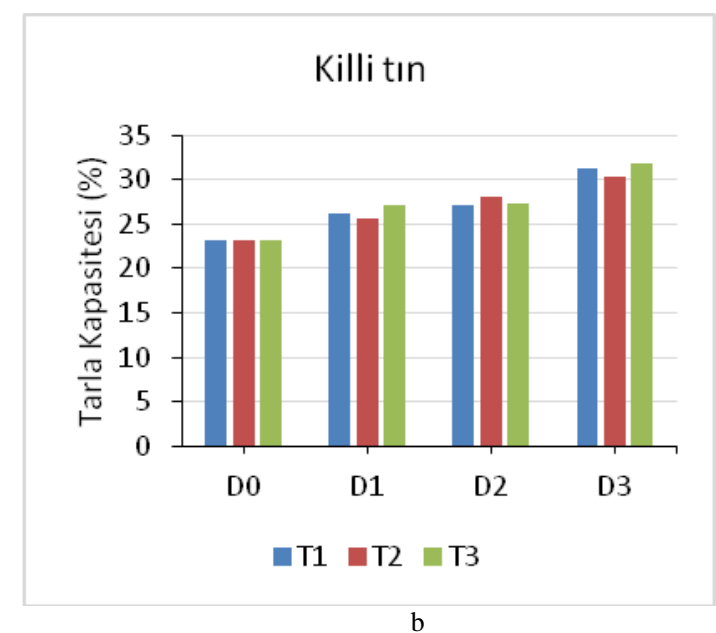

Şekil 1. Killi tın toprakta kokopit uygulamasının tarla kapasitesi üzerine etkisi. D: Dozların seviyesi, T: İnkübasyon süreleri.

Figure 1. Effect of cocopeat application on field capacity in clay loam soil. D: Level of doses, T: Incubation times.
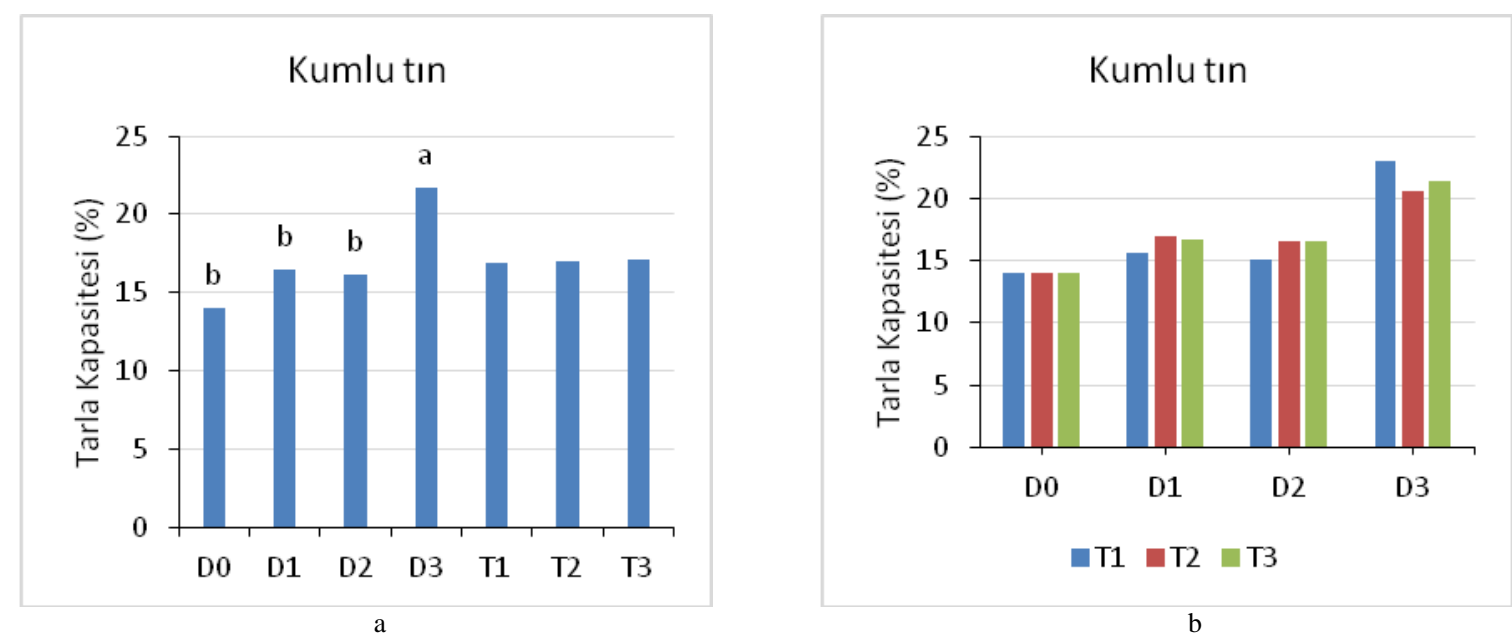

Şekil 2. Kumlu tın toprakta kokopit uygulamasının tarla kapasitesi üzerine etkisi. D: Dozların seviyesi, T: İnkübasyon süreleri.

Figure 2. Effect of cocopeat application on field capacity in sandy soil. D: Level of doses, T: Incubation times. 
Hem killi hem de kumlu toprakta inkübasyon süresine bağl1 olarak TK seviyesinde önemli bir artış gözlenmemiştir. Killi toprakta D0, D2 ve D3'e göre farkl1 belirlenirken kumlu topraklarda D0, D1 ve D2 ile benzer bulunmuştur. Hem kumlu hem de killi topraklarda en yüksek su artışı D3 dozunda belirlenmiştir. Artan dozlarda kokopit uygulamalarının -10 $\mathrm{kPa}$ 'da tutulan nem içeriğinde artış sağladığ 1 Arachchi ve Somasiri (1997) tarafindan belirtilmiştir. Artan dozda farklı toprak düzenleyici uygulamaları toprakların TK ve SN'lerini arttırmaktadır (Özdemir ve ark. 2014). Ayrıca, organik atık uygulamaları ile kil ve tınlı kum bünyeli toprakların su tutma kapasiteleri, diğer bazı fiziksel ve kimyasal özellikleri olumlu yönde etkilenmektedir (Candemir ve Gülser 2011).

Killi topraklara uygulanan kokopitin devamlı solma noktası üzerine etkisi Şekil 3'de belirtilmiştir. İnkübasyon süresi ile dozun interaksiyonu önemli bulunmazken, doz uygulamalarındaki değişim devamlı solma noktasında (SN) istatistiksel olarak önemli bulunmuş $(\mathrm{P}<0.01)$ ve killi toprakların devamlı solma noktası \%11.3-13.4 arasında değişim göstermiştir. Doz uygulamaları arasında en yüksek devamlı solma noktas1 \%13.3 ile D3'de belirlenirken, D3, D2 ve D1 uygulamalarında istatistiksel olarak birbirine benzer sonuçlar

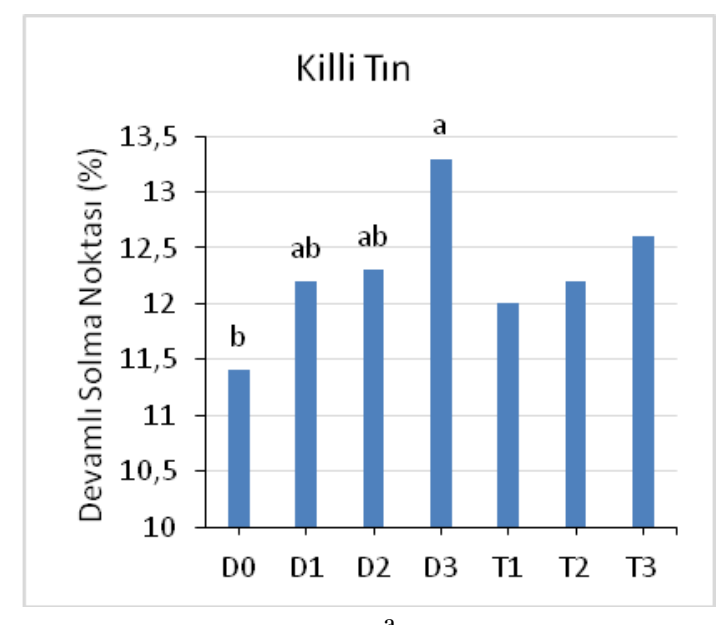

gözlemlenmiş, en düşük SN ise D0'da bulunmuştur (Şekil 3a). Kontrol uygulamasına göre D3 doz uygulamasında da \%1.18'lik bir artış gözlenmiştir. Artan inkübasyon sürelerine bağlı olarak SN değerleri sırasıyla \%12,12.2, 12.6 olarak artış göstermiş fakat bu artış istatistiksel olarak önemli bulunmamıştır. Uygulamaların interaksiyonları incelendiğinde en yüksek SN, T3'ün D3 dozunda, en düşük ise T1'in D0 dozunda belirlenmiştir (Şekil 3b). Organik bir materyal olan kokopitin su tutma üzerine etkisi olduğu görülmektedir. Organik madde ile tarla kapasitesi ve devaml 1 solma noktası arasinda anlamlı ilişkilerin $\left(\mathrm{R}^{2}: 0.567,0.644\right)$ olduğu literatürlerde de belirtmiștir (Gülser 2004). Yine Yangyuoru ve ark. (2006) kokopit uygulaması ile sulamadan 5 gün sonra, kontrole kıyasla $\% 100$ daha fazla suyun tutulduğunu belirtmişlerdir. Ayrıca, organik düzenleyicilerin zamanla parçalanıp ayrışarak etkisini yitirmesinden dolayı sentetik düzenleyiciler üzerine daha fazla odaklanılabilmektedir.

Kumlu toprağa kokopit uygulamalarının etkisi Şekil 4'de belirtilmiş̧ir. Uygulamaların ana etkilerinden doz uygulamaları istatistik olarak önemli $(\mathrm{P}<0.05)$ doz, inkübasyon süresi interaksiyonu ise önemsiz bulunmuştur. Toprakların SN değerleri \%6.86-10.67 arasında değişim göstermiş,

Şekil 3. Killi tın toprakta kokopit uygulamasının devamlı solma noktası üzerine etkisi. D: Dozların seviyesi, T: İnkübasyon süreleri.

Figure 3. The effect of cocopeat application on permanent wilting point in clay soil. D: Level of doses, T: Incubation times.
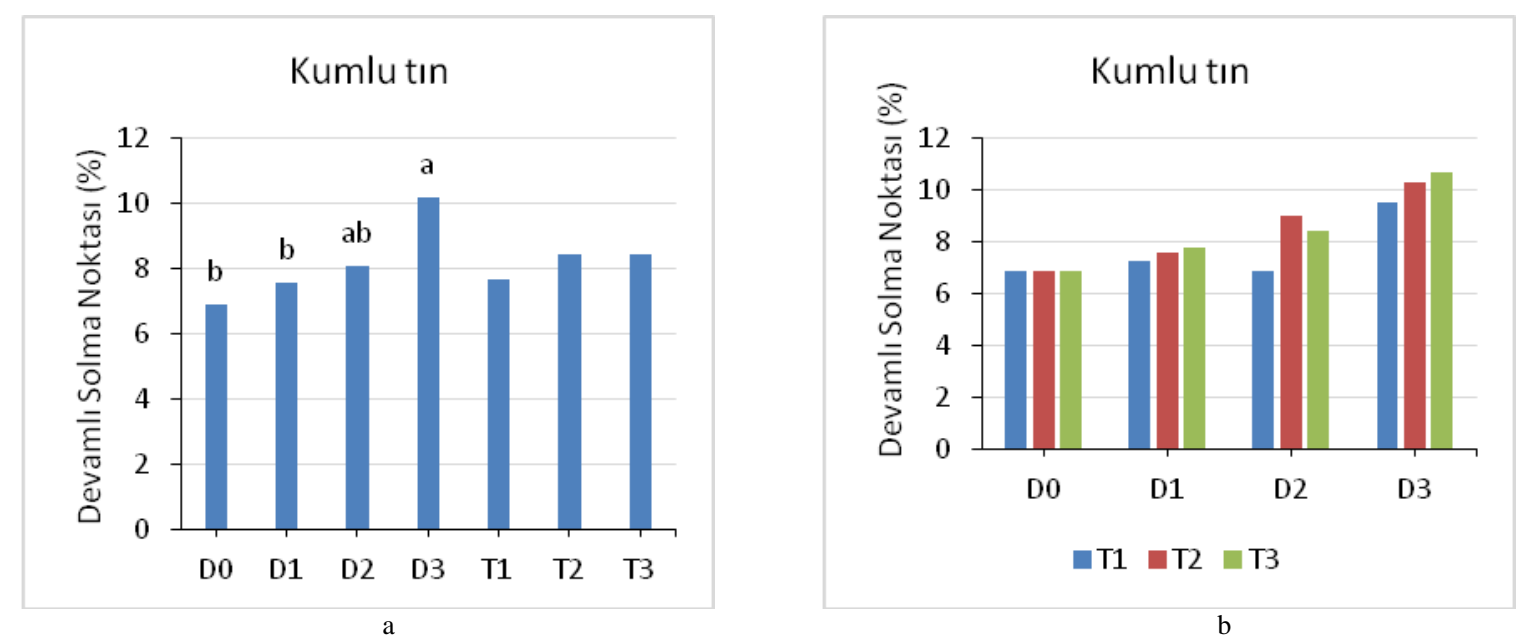

Şekil 4. Kumlu tın toprakta kokopit uygulamasının devamlı solma noktası üzerine etkisi. D: Dozların seviyesi, T: İnkübasyon süreleri.

Figure 4. Effect of cocopeat application on permanent wilting point in sandy soil. D: Level of doses, T: Incubation times. 
inkübasyon süresine bağl1 olarak T1 süresinde \%7.63 olan SN T2 ve T3'de benzer (\%8.42) bulunmuştur (Şekil 4a). Doz uygulamalarının etkisinde en yüksek SN, D3 (10.17) en düşük ise D0 dozunda $(\% 6.87)$ belirlenmiştir. D0, D1 ve D2 uygulamaları istatistik olarak birbirine benzer iken, D3 dozu D0 ve D1 doz uygulamalarından istatistiksel olarak farkl1, D2 ile D3 doz uygulamaları ise istatistiksel olarak benzer sonuçlar sergilemiştir (Şekil 4a). Uygulamaların interaksiyonları incelendiğinde değişim istatistiksel olarak önemli olmasa da en düşük SN, T2'nin D0 (\%6.86) en yüksek ise T3'ün D3 (\%10.67) uygulamasında bulunmuştur. Kontrole göre kokopit uygulamalarıyla kumlu toprakların SN'sinde \%3.81'lik bir artış gözlenmiştir (Şekil 4b). Özellikle kumlu topraklara uygulanan organik madde, suyu kendi bünyesinde tutarak yararlı su boşluklarını arttırmaktadır (Yılmaz ve Alagöz 2008).

Killi toprakta inkübasyon süresince düşük seviyelerde artış gösteren SN, kumlu toprakta T2 ve T3 süresince sabit kalmıştır. Killi toprakta doz uygulamalarına bağlı olarak genel bir artış olsa da bu artışlar istatistiksel olarak önemli bulunmuştur. Kumlu topraklarda ise D3 dozu D0 ve D1 doz uygulamasina göre farkl1lık sergilemiştir. Genel olarak SN incelendiğinde kumlu topraklara uygulanan kokopit SN'de fazla artışa sebep olmamıştır. Düşük su tutma kapasitesine sahip materyallere kokopit uygulamaları ile daha iyi sonuçlar elde edilmekte (Ilahi ve Ahmad 2017) olup organik bir atık olarak değerlendirilen kokopit'in \%6.3 oranında kumlu topraklara uygulanmasıyla ideal su tutma kapasitesine ulaştığı literatürlerde bildirilmiştir (Arachchi ve Somasiri 1997).

Tüm tekstür grupları için kokopit uygulama dozlarının TK üzerine etkileri incelendiğinde D3 uygulaması diğer dozlardan istatistiksel olarak önemli bir değişim göstererek söz konusu uygulamayla en yüksek TK elde edilmiştir. Fakat SN'de D3 ve D2 arasında istatistiksel bir farklılık bulunmamış, TK' daki aynı etki SN'de görülmemiştir. Söz konusu bu farklılık uygulanan materyalin gözenek yapısı ile ilgili olabilmektedir. Devamlı solma noktası üzerinde mikro gözenekliliğin daha etkili olduğu bilinmektedir (Reeve 1986). Ayrıca kokopitin ince fraksiyonunun kaba lifli durumuna göre daha fazla su tutma özelliğine sahip olduğu çalışmalarda bildirilmiştir (Lodolini ve ark. 2017).

\section{Sonuç ve Öneriler}

$\mathrm{Bu}$ çalışmada, farklı dozlarda kokopit uygulamalarının inkübasyon süresine bağlı olarak farklı tekstürde (kumlu tın ve killi tın) toprakların tarla kapasitesi ve devamlı solma noktası nem sabiteleri üzerine etkisi araştırılmıştır. İnkübasyon süresine bağlı olarak nem sabitelerinde istatistiksel olarak önemli seviyede değişimler belirlenememiştir. Kokopit uygulamalarının, ekonomik olarak uygulanabilirliği göz önüne alındığında devamlı solma noktasındaki optimum artışın D2 ile sağlandığ 1 bulunmuştur. Her iki toprak grubu için tarla kapasitesindeki en iyi artıs ise D3 uygulamasında belirlenmiştir. Kumlu ve killi topraklarda D3 ile tarla kapasitesi yaklaşık \%8 oranında artarken, killi topraklarda devamlı solma noktası $\% 1.18$, kumlu topraklarda ise \%3.81 seviyelerinde artış göstermiştir.

Çalışma sonunda, orta ve kaba bünyeli topraklarda su tutma kapasitesinin artırılması, sulama zamanlarının azaltılması ve genellikle bölgede bağ ve gül yetiştiricilikleri yapılan kumlu tın tekstürlü topraklarda suyun etkili kullanımı için kokopit materyalinin kullanılabileceği belirlenmiştir. Ayrıca benzer çalışmaların arazi koşullarında, daha yüksek dozlar ve daha küçük parçacık boyutuyla denenmesinin, problemli olan toprak koşullarının iyileştirilmesi adına etkili olacağı düşünülmektedir.

\section{Kaynaklar}

Abad M, Noguera P, Puchades R, Maquieira A, Noguera V (2002) Physico-chemical and chemical properties of some coconut coir dusts for use as a peat substitute for containerised ornamental plants. Bioresource Technology 82(3): 241-245.

Abdelfattah MA (2013) Pedogenesis, land management and soil classification in hyper- arid environments: results and implications from a case study in the United Arab Emirates. Soil Use and Management 29(2): 279-294.

Arachchi LV, Somasiri LLW (1997) Use of coir dust on the productivity of coconut on sandy soils. In Cocos (12): 54-71.

Bhardwaj AK, Shainberg I, Goldstein D, Warrington DN, Levy GJ (2007) Water retention and hydraulic conductivity of cross-linked polyacrylamides in sandy soils. Soil Science Society of America Journal 71(2): 406-412.

Bhosale PR, Chonde SG, Nakade DB, Raut PD (2012) Studies on physico-chemical characteristics of waxed and dewaxed pressmud and its effect on water holding capacity of soil. ISCA Journal of Biological Sciences 1(1): 35-41.

Candemir F, Gülser C (2011) Effects of different agricultural wastes on some soil quality indexes at clay and loamy sand fields. Communications in Soil Science and Plant Analysis 42(1): 13-28.

Dahnke WC, Whitney DA (1988) Measurement of soil salinity. Recommended Chemical Soil Test Procedures for the North Central Region 221: 32-34.

Demiralay İ (1993) Toprak Fiziksel Analizleri. Atatürk Üniversitesi Ziraat Fakültesi Yayınları, Erzurum.

Evans MR, Konduru S, Stamps RH (1996) Source variation in physical and chemical properties of coconut coir dust. HortScience 31(6): 965-967.

Gülser C (2004) Tarla kapasitesi ve devamlı solma noktası değerlerinin toprakların fiziksel ve kimyasal özellikleriyle ilişkili pedotransfer eşitliklerle belirlenmesi. Ondokuz Mayıs Üniversitesi Ziraat Fakültesi Dergisi 19(3): 19-23.

Ilahi WFF, Ahmad D (2017) A study on the physical and hydraulic characteristics of cocopeat perlite mixture as a growing media in containerized plant production. Sains Malaysiana 46(6): 975-980.

Ippolito JA, Tarkalson DD, Lehrsch GA (2011) Zeolite soil application method affects inorganic nitrogen, moisture, and corn growth. Soil Science 176(3): 136-142.

Jones Jr JB (1984) A Laboratory Guide of Exercises in Conducting Soil Test, and Plant Analyses. No. 631.42 J6.

Kacar B (2009) Toprak Analizleri. Nobel Yayın Dağıtım, Ankara.

Kadıoğlu B, Canbolat MY (2019) Organik ve inorganik materyallerin ince bünyeli toprağa ilavesi ile hazırlanan yetişme ortamlarının hidrofiziksel özellikleri. Atatürk Üniversitesi Ziraat Fakültesi Dergisi 50(2): 107-114.

Korkanç SY, Çimen Ş, Aklan F, Arabacıoğlu R, Köprülü H (2017) Bazı toprak iyileştiricilerin toprakların hidro-fiziksel ve kimyasal özelliklerine etkileri. Türkiye Ormancılık Dergisi 18(2): 125-132.

Lodolini EM, Pica F, Massetani F, Neri D (2017) Physical, chemical and biological properties of some alternative growing substrates. European Journal of Science 12(1): 32-38.

Meral R, Demir AD, Demir Y, Malasli MZ, Turan V (2015) The improvement of soil water holding capacity, infiltration rate, and aggregate stability with different soil conditioners. Fresensius Environmental Bulletin 24(11): 3550-3555.

Minitap (2020) Versiyon 19. http://www.minitab.com/enus/products/minitab/. Erişim 01 Ocak 2020. 
Özdemir N, Gülser C, Ekberli İ, Kop ÖT (2014) Asit toprakta düzenleyici uygulamalarının bazı toprak özellikleri ve verime etkileri. Toprak Bilimi ve Bitki Besleme Dergisi 2(1): 27-32.

Reeve MJ (1986) Water retention, porosity, and composition interrelationships of alluvial soils in mid Hawke's Bay and their relevance in irrigation planning. New Zealand Journal of Agricultural Research 29(3): 457-468.

Thombare N, Mishra S, Siddiqui MZ, Jha U, Singh D, Mahajan GR (2018) Design and development of guar gum based novel, superabsorbent and moisture retaining hydrogels for agricultural applications. Carbohydrate Polymers 185: 169-178.

US Salinity Laboratory Staff (1954) Diagnosis and improvement of salina and alkali soils. Agricultural Handbook 60, U.S.D.A.

Ülgen N, Yurtsever N (1988) Türkiye Gübre ve Gübreleme Rehberi. 3. Baskı, TC Tarım Orman Köyişleri Bakanlığı, Köy Hizmetleri Genel Müdürlüğü, Toprak ve Gübre Araştırma Enstitüsü Müdürlüğü Yayınları, Genel Yayın, Ankara.
Vijayalakshmi V, Nemichandrappa M, Reddy K.S, Ayyanagowdar MS (2012) Effect of polymers on moisture retention and soil water holding capacity. Karnataka Journal of Agricultural Sciences 25(4): 469-471.

Xu S, Zhang L, McLaughlin NB, Mi J, Chen Q, Liu J (2015) Effect of synthetic and natural water absorbing soil amendment soil physical properties under potato production in a semi-arid region. Soil and Tillage Research 148: 31-39.

Yangyuoru M, Boateng E, Adiku SGK, Acquah D, Adjadeh TA, Mawunya F (2006) Effects of natural and synthetic soil conditioners on soil moisture retention and maize yield. West Africa Journal of Applied Ecology (WAJAE) 9(1): 6-18.

Yılmaz E, Alagöz Z (2008) Organik madde toprak suyu ilişkisi. Türk Bilimsel Derlemeler Dergisi 1(2): 15-21. 